\begin{tabular}{|c|c|c|}
\hline Caco Dor & \multicolumn{2}{|l|}{ Case Rep Gastroenterol 2018;12:532-539 } \\
\hline Gastroenterology & $\begin{array}{l}\text { DOI: } 10.1159 / 000490906 \\
\text { Published online: August 31, } 2018\end{array}$ & $\begin{array}{l}\text { (c) } 2018 \text { The Author(s) } \\
\text { Published by S. Karger AG, Basel } \\
\text { www.karger.com/crg }\end{array}$ \\
\hline & $\begin{array}{l}\text { This article is licensed under the Creative } \\
\text { NoDerivatives } 4.0 \quad \text { International } \\
\text { (http://www.karger.com/Services/OpenAccessLicer } \\
\text { commercial purposes as well as any distribution } \\
\text { permission. }\end{array}$ & $\begin{array}{l}\text { ommons Attribution-NonCommercial- } \\
\text { License (CC BY-NC-ND) } \\
\text { e). Usage and distribution for } \\
\text { of modified material requires written }\end{array}$ \\
\hline
\end{tabular}

This article is licensed under the Creative Commons Attribution-NonCommercial(http://www.karger.com/Services/OpenAccessLicense). Usage and distribution for permission.

\title{
Long-Term Survival in Gastroesophageal Junction Adenocarcinoma: Ramucirumab
}

\author{
Maria Angeles Gil-Delgado ${ }^{a} \quad$ Olivier Lucidarme $^{b} \quad$ Jean Baptiste Bachet ${ }^{c}$ \\ Naima Mahi ${ }^{d}$ David Khayat ${ }^{a}$ \\ aMedical Oncology Service, Groupe Hospitalier Pitié Salpêtrière, Paris, France; ${ }^{b}$ Radiology \\ Department, Pitié-Salpêtrière Hospital, Assistance Publique-Hôpitaux de Paris, Sorbonne \\ University, CNRS, INSERM, Laboratoire d'Imagerie Biomédicale (LIB), Paris, France; \\ 'Sorbonne University, UPMC University, Gastrointestinal Diseases Service, Groupe \\ Hospitalier Pitié Salpêtrière, Paris, France; ${ }^{d}$ Eli Lilly France, Neuilly-sur-Seine, France
}

\section{Keywords}

Gastric cancer · Ramucirumab · Survival

\begin{abstract}
We report a case of long-term survival with complete response of liver metastases within RAINBOW, a randomized, controlled trial of ramucirumab $8 \mathrm{mg} / \mathrm{kg}$ intravenously (days 1,15 ) versus placebo, both plus paclitaxel $80 \mathrm{mg} / \mathrm{m}^{2}$ intravenously (days $1,8,15$ ), every 4 weeks in patients with previously treated advanced gastroesophageal junction adenocarcinoma. A 64year-old man with gastroesophageal junction adenocarcinoma and liver metastases received first-line folinic acid, 5-fluorouracil plus oxaliplatin (FOLFOX) following jejunostomy. On liver progression, he enrolled in RAINBOW (April 2012), receiving ramucirumab. In November 2013, positron emission tomography scan was consistent with complete metabolic response, confirmed by a follow-up scan in March 2016.

(C) 2018 The Author(s) Published by S. Karger AG, Basel
\end{abstract}




\section{Introduction}

Locally advanced or metastatic gastroesophageal junction adenocarcinoma, which has a median survival of 7-11 months [1], is typically treated with cytotoxic chemotherapy [2]. Clinical guidelines recommend 2 drug regimens involving a platinum-based compound (oxaliplatin or cisplatin) and a fluoropyrimidine (fluorouracil or capecitabine) as first-line therapy $[2,3]$. Until recently, no second-line regimen has been approved in the USA or Europe.

The vascular endothelial growth factor (VEGF) pathway regulates angiogenesis, a fundamental event in tumor growth and metastatic dissemination. VEGF receptor pathway activation promotes endothelial cell growth, migration, and survival [4]. In preclinical models, antiVEGF/VEGF receptor therapies show potent inhibition of angiogenesis and tumor growth [5]. In patients with gastric cancer, high VEGF levels are associated with increased tumor aggressiveness and reduced survival [6].

Ramucirumab (Cyramza ${ }^{\circledR}$, Eli Lilly) is a direct VEGF receptor 2 inhibitor. This fully human immunoglobulin G1 monoclonal antibody binds to the extracellular VEGF-binding domain with high specificity and affinity, preventing ligand binding [7]. Ramucirumab is the first biological treatment given as monotherapy to demonstrate survival benefits in patients with advanced gastric or gastroesophageal junction adenocarcinoma progressing after first-line chemotherapy. Patients with this clinical history who enrolled in REGARD, a randomized, double-blind, placebo-controlled, phase III trial, showed significantly longer overall survival with ramucirumab than placebo (median 5.2 vs. 3.8 months; hazard ratio $0.776 ; p=0.047$ ) [8]. The RAINBOW study (NCT01170663) was a randomized, double-blind, placebo-controlled, phase III trial designed to establish whether ramucirumab conferred a survival advantage in paclitaxel-treated patients with advanced gastric or gastroesophageal junction adenocarcinoma and disease progression after first-line combination chemotherapy. In RAINBOW, overall survival was significantly longer in the ramucirumab/paclitaxel group than in the placebo/paclitaxel group (median 9.6 vs. 7.4 months; hazard ratio 0.807; $p=0.017$ ) [9]. We discuss a patient with liver metastases who achieved complete response without surgery in the RAINBOW trial.

\section{Case Report}

A 64-year-old man with a history of prostate cancer treated with radical prostatectomy in 2005 and untreated hypercholesterolemia experienced progressive dysphagia and weight loss over 3 weeks in November 2011 (12 kg; initial body weight [BW]: $93 \mathrm{~kg}$, last BW: $115 \mathrm{~kg}$; normal patient BW: 114-116 kg). Ultrasound endoscopy (December 2011) showed complete stenosis of the lower esophagus, 39-42 cm from the dental arch. Histology indicated moderately differentiated adenocarcinoma; human epidermal growth factor receptor 2 was not overexpressed. A total body computed tomography (CT) scan showed liver metastases and 2 enlarged abdominal lateral-aortic lymph nodes. Carcinoembryonic antigen (CEA) and carbohydrate antigen (CA) 19-9 values were normal. In January 2012, he underwent jejunostomy and received folinic acid, 5-fluorouracil plus oxaliplatin (FOLFOX) first-line therapy.

In April 2012, after 5 FOLFOX courses, the patient experienced liver progression. He enrolled in the RAINBOW trial and was randomized the same month. His baseline characteristics at entry were: BW, $95 \mathrm{~kg}$; Eastern Cooperative Oncology Group/World Health Organization Performance Status (ECOG/WHO PS), 1; blood pressure (BP), 140/90 mm Hg; heart rate, 68 beats/minute. At baseline, he had grade (G) 1 neuropathy (grading based on National Cancer 
Institute Common Terminology Criteria for Adverse Events, version 4.02 [10]) due to previous oxaliplatin treatment. The patient had no proteinuria, normal left ventricular ejection fraction (LVEF), and no history of thromboembolic or bleeding events. Baseline chest, abdomen, and pelvic CT scans showed multiple liver metastases, two of which were selected for evaluation of therapeutic response (segment VIII, $20 \mathrm{~mm}$ diameter; center of right lobe, $26 \mathrm{~mm}$ diameter) (Fig. 1).

At the end of April 2012, the patient started intravenous paclitaxel plus blinded ramucirumab/placebo treatment on a 4 -week cycle (days 1 and 15 , ramucirumab $8 \mathrm{mg} / \mathrm{kg}$; days 1 , 8 , and 15, paclitaxel $80 \mathrm{mg} / \mathrm{m}^{2}$ ). After the first cycle, there was rapid clinical improvement, including a 3-kg increase in BW without a jejunostomy tube, which the patient removed himself.

The first CT assessment scan, performed after cycle 2 (week 8), showed a partial response (PR) of $\approx 47 \%$ (PR defined according to Response Evaluation Criteria in Solid Tumors [RECIST] version 1.1 [ $\geq 30 \%$ decrease from baseline in sum of longest diameter of target lesions] [11]); no G3-4 toxicity was observed.

In September 2012 (cycle 6), the patient developed G2 neuropathy related to paclitaxel therapy, prompting a dose reduction to $70 \mathrm{mg} / \mathrm{m}^{2}$. His ECOG/WHO PS was 0 , blood cell count (BCC), blood chemistry, and proteinuria were normal, and there was no change in LVEF (75\%) or BP.

In November 2012 (after 8 cycles), a CT scan demonstrated a PR of $\approx 80 \%$. Other parameters included: ECOG/WHO PS, 0; BW, $104 \mathrm{~kg}$; normal BP, BCC, and blood chemistry; proteinuria, $0.07 \mathrm{~g} / \mathrm{L}$; persistent G2 neuropathy. In March 2013 (after 12 cycles), neuropathy increased from G2 to G3. Electromyography showed severe axonal sensory-motor polyneuropathy. Paclitaxel therapy was stopped but treatment with ramucirumab continued, in accordance with the protocol.

In May 2013, a CT scan confirmed an $\approx 85 \%$ PR (Fig. 2). Other parameters included ECOG/WHO PS, 0; BW, 109 kg; proteinuria, $<0.06$ g/L. BCC, BP, LVEF (78\%), and tumor markers (CEA and CA 19-9) were unchanged. Development of G3 hypertension without renal impairment required combination therapy with irbesartan/hydrochlorothiazide 300/12.5 mg, nebivolol $5 \mathrm{mg}$, and lercanidipine $20 \mathrm{mg}$. Gastric endoscopy and biopsies (June 2013) were consistent with inflammation and low-grade dysplasia; malignancy was not evident.

In October 2013, tests showed progressive increase in liver enzyme levels, particularly gamma-glutamyl transferase (GGT) (600 IU) and serum glutamic-oxaloacetic transaminase/serum glutamic-pyruvic transaminase ( $>1.5$ times normal), indicative of hepatic cytolysis and cholestatic changes. Bilirubin and prothrombin time were not increased. Ultrasound indicated liver steatosis, which was deemed unrelated to ramucirumab therapy. Tumor markers were normal.

In November 2013, the trial was unblinded. The patient continued treatment with ramucirumab $8 \mathrm{mg} / \mathrm{m}^{2}$. Positron emission tomography (PET) indicated a complete metabolic response at that time.

In May 2014, a follow-up CT scan showed 1 remaining hypoattenuating residual lesion ( $<5 \mathrm{~mm}$ diameter, subcapsular portion of segment VIII) and a 14-mm hypervascularized nodule (segment IV). This new abnormality was considered regenerative nodular hyperplasia. Hepatic magnetic resonance imaging (July 2014) revealed that the focal liver lesion detected in May had increased from 14 to $31 \mathrm{~mm}$ and that 4 new smaller lesions were visible, with an imaging pattern not suggestive of metastases (no diffusion restriction, hypervascularized). A subsequent ${ }^{18} \mathrm{~F}-$-fluorodeoxyglucose (FDG) PET-CT scan (July 2014) showed no suspicious hypermetabolism in the liver or elsewhere (Fig. 3). Focal liver lesions were considered benign 
and probably due to peliosis. BCC, blood chemistry, renal function, and BP were normal (under antihypertensive therapy). G2 neuropathy was persistent but did not alter the patient's ECOG/WHO PS, which remained at 0. Ramucirumab was continued using the same schedule.

In May 2016, following a cardiologic workup for exertional dyspnea, the patient was diagnosed with pulmonary hypertension possibly related to study treatment. However, exertional dyspnea had been known since before enrollment into RAINBOW, and treatment with ramucirumab was continued. The last dose of ramucirumab was administered in December 2016, after which the patient and medical teams elected to permanently stop treatment.

Currently, the patient is doing well (ECOG/WHO PS, 0; BW, $118 \mathrm{~kg}$; normal BCC, blood chemistry [except grade I GGT], renal function, and BP [without antihypertensive therapy]; neuropathy persistent but improved). The last CT scan (March 2016) showed that the hypervascularized lesions (putative peliosis) were unchanged compared with July 2014 and the most recent ${ }^{18}$ F-FDG PET-CT scan (March 2016) was negative; the patient was still considered to have achieved a complete metabolic response. The patient continues to experience a goodquality, normal life, and travels abroad in August 2017 without any further anticancer treatment.

\section{Conclusion}

The long survival of this patient with metastatic gastroesophageal junction adenocarcinoma is clearly due to ramucirumab/paclitaxel combination therapy followed by ramucirumab alone, without surgery. Ramucirumab, as monotherapy or in combination with paclitaxel, is approved for second-line treatment of gastroesophageal junction adenocarcinoma that has progressed on fluoropyrimidine- or platinum-containing therapy [12]. Notably, the survival of this patient ( 5 years) is considerably greater than the median survival reported for similar patients receiving first-line therapy only (9.5-12.3 months) [13, 14]. Prior to second-line therapy, the patient had good PS (ECOG/WHO PS 1) that continues to be maintained (ECOG/WHO PS 0 from cycle 6 to last follow-up). In August 2017, the patient was confirmed to be alive with a very good PS (ECOG/WHO PS 0).

Patients in the ramucirumab/paclitaxel group of RAINBOW had a higher incidence of G3 and G4 adverse events than the placebo/paclitaxel group, including neutropenia (G3 and G4) and hypertension (G3) [9]. Although the patient reported here experienced these adverse events, they did not affect his well-being (as measured by ECOG/WHO PS).

This patient developed peliosis, an uncommon vascular condition of uncertain pathogenesis [15]. Peliosis has been associated with several malignancies, including hepatocellular carcinoma, and a number of drugs, including methotrexate, azathioprine [15], and targeted therapy, as this has also been observed in patients responsive to anti-VEGF compounds, particularly with bevacizumab (personal observation in the clinic). The patient has definitively stopped ramucirumab treatment in agreement with the investigator.

This case supports the main finding of the RAINBOW trial that combining ramucirumab with paclitaxel significantly increases overall survival compared with placebo/paclitaxel in patients with previously treated advanced gastric or gastroesophageal junction adenocarcinoma [9]. The outcome of this patient, who could not tolerate long-term paclitaxel therapy, contributes to the knowledge concerning ramucirumab monotherapy. We have found that discontinuing paclitaxel while continuing ramucirumab monotherapy is feasible and may contribute to improved outcomes in such patients. 


\section{Acknowledgement}

The authors would like to acknowledge Dr. Duncan Marriott and Dr. Gill Gummer (Rx Communications, Mold, UK) for medical writing assistance with the preparation of this case report, funded by Eli Lilly (Indianapolis, IN, USA), and Dr. Nathanael Jeni (Groupe Hospitalier Pitié Salpêtrière, Paris, France) who conducted the PET scanning. The CT scan and MRI pictures and figures were provided by Prof. Olivier Lucidarme.

\section{Statement of Ethics}

All procedures followed were in accordance with the ethical standards of the responsible committee on human experimentation (institutional and national) and with the Helsinki Declaration of 1964 and later versions.

Informed consent to be included in this study was obtained from the patient.

\section{Disclosure Statement}

Dr. J.B. Bachet has received personal fees from Amgen, Bayer, Celgene, Merck Serono, Roche, Sanofi, Servier, and nonfinancial support from Amgen, Merck Serono, and Roche.

Dr. M.A. Gil-Delgado has received a fee from Celtic Biotech as Principal Investigator in a phase I trial.

Dr. O. Lucidarme, Dr. N. Mahi, and Prof. D. Khayat declare no conflicts of interest.

\section{References}

1 Luo HY, Xu RH. Novel targeted therapy for advanced gastric cancer. Biochem Pharmacol. 2014;4:1-8.

2 Smyth EC, Verheij M, Allum W, Cunningham D, Cervantes A, Arnold D; ESMO Guidelines Committee. Gastric cancer: ESMO Clinical Practice Guidelines for diagnosis, treatment and follow-up. Ann Oncol. 2016 Sep;27 suppl 5:v38-49.

3 Ajani JA, D'Amico TA, Almhanna K, Bentrem DJ, Chao J, Das P, et al. Gastric Cancer, Version 3.2016, NCCN Clinical Practice Guidelines in Oncology. J Natl Compr Canc Netw. 2016 Oct;14(10):1286-312.

4 Rockwell S, Knisely JP. Hypoxia and angiogenesis in experimental tumor models: therapeutic implications. In: Goldberg ID, Rosen EM, editors. Regulation of angiogenesis. Basel: Birkhaüser Verlag; 1997. pp. 335-60.

5 Hicklin DJ, Ellis LM. Role of the vascular endothelial growth factor pathway in tumor growth and angiogenesis. J Clin Oncol. 2005 Feb;23(5):1011-27.

6 Brzozowa M, Michalski M, Harabin-Słowińska M, Wojnicz R. The role of tumour microenvironment in gastric cancer angiogenesis. Prz Gastroenterol. 2014;9(6):325-8.

7 Fontanella C, Ongaro E, Bolzonello S, Guardascione M, Fasola G, Aprile G. Clinical advances in the development of novel VEGFR2 inhibitors. Ann Transl Med. 2014 Dec;2(12):123.

8 Fuchs CS, Tomasek J, Yong CJ, Dumitru F, Passalacqua R, Goswami C, et al.; REGARD Trial Investigators. Ramucirumab monotherapy for previously treated advanced gastric or gastro-oesophageal junction adenocarcinoma (REGARD): an international, randomised, multicentre, placebo-controlled, phase 3 trial. Lancet. 2014 Jan;383(9911):31-9.

9 Wilke H, Muro K, Van Cutsem E, Oh SC, Bodoky G, Shimada Y, et al.; RAINBOW Study Group. Ramucirumab plus paclitaxel versus placebo plus paclitaxel in patients with previously treated advanced gastric or gastrooesophageal junction adenocarcinoma (RAINBOW): a double-blind, randomised phase 3 trial. Lancet Oncol. 2014 Oct;15(11):1224-35.

10 Cancer Therapy Evaluation Program. Common Terminology Criteria for Adverse Events v4.0. 2009 [accessed February 28, 2014]. Available from: http://ctep.cancer.gov/protocolDevelopment/electronic_applications/ctc.htm\#ctc_40.

11 Eisenhauer EA, Therasse P, Bogaerts J, Schwartz LH, Sargent D, Ford R, et al. New response evaluation criteria in solid tumours: revised RECIST guideline (version 1.1). Eur J Cancer. 2009 Jan;45(2):228-47. 
12 Eli Lilly and Company. Cyramza Prescribing Information. 2016 [accessed February 8, 2017]. Available from: http://pi.lilly.com/us/cyramza-pi.pdf.

13 Ochenduszko S, Puskulluoglu M, Konopka K, Fijorek K, Urbanczyk K, Budzynski A, et al. Comparison of efficacy and safety of first-line palliative chemotherapy with EOX and mDCF regimens in patients with locally advanced inoperable or metastatic HER2-negative gastric or gastroesophageal junction adenocarcinoma: a randomized phase 3 trial. Med Oncol. 2015 0ct;32(10):242.

14 Shah MA, Ramanathan RK, Ilson DH, Levnor A, D'Adamo D, O’Reilly E, et al. Multicenter phase II study of irinotecan, cisplatin, and bevacizumab in patients with metastatic gastric or gastroesophageal junction adenocarcinoma. J Clin Oncol. 2006 Nov;24(33):5201-6.

15 Crocetti D, Palmieri A, Pedullà G, Pasta V, D’Orazi V, Grazi GL. Peliosis hepatis: personal experience and literature review. World J Gastroenterol. 2015 Dec;21(46):13188-94.
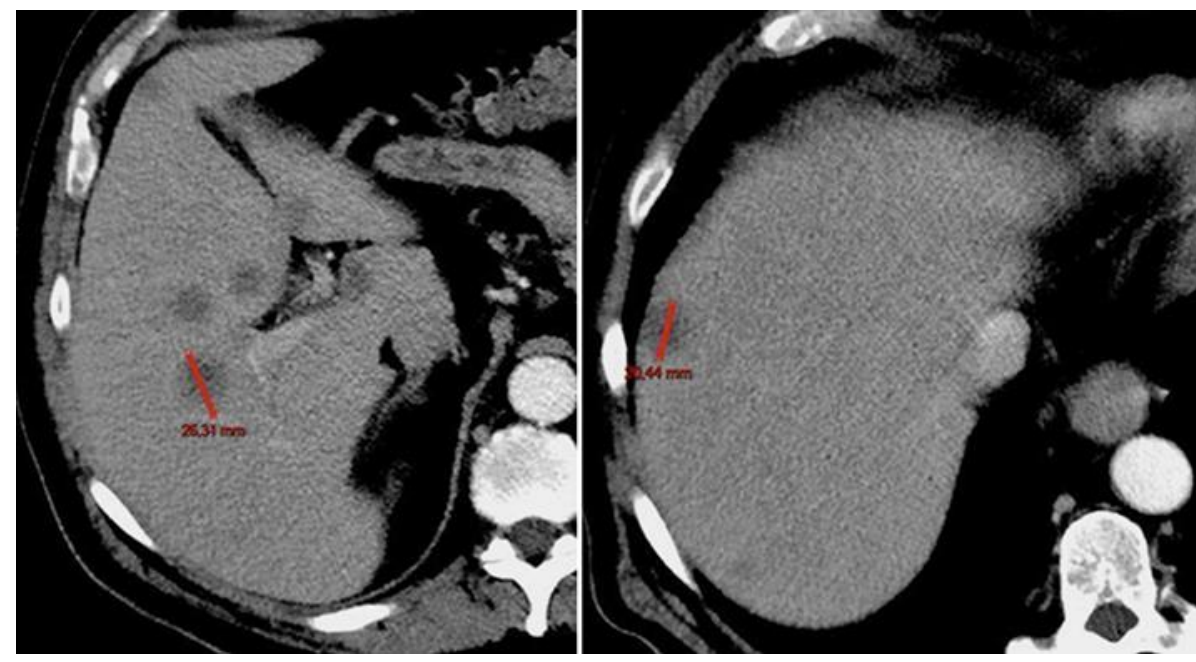

Fig. 1. Baseline computed tomography examination (04/19/2012) showing multiple hypoattenuating focal liver lesions. Two (calipers) were considered target lesions for the assessment of therapy. The sum of the longest diameter was $47 \mathrm{~mm}(820.4+26.3 \mathrm{~mm})$. 


\begin{tabular}{ll|l} 
Case Reports in & $\begin{array}{l}\text { Case Rep Gastroenterol 2018;12:532-539 } \\
\text { Gastroenterology }\end{array}$ & $\begin{array}{l}\text { ○ } 2018 \text { The Author(s). Published by S. Karger AG, Basel } \\
\text { www.karger.com/crg }\end{array}$ \\
\hline
\end{tabular}

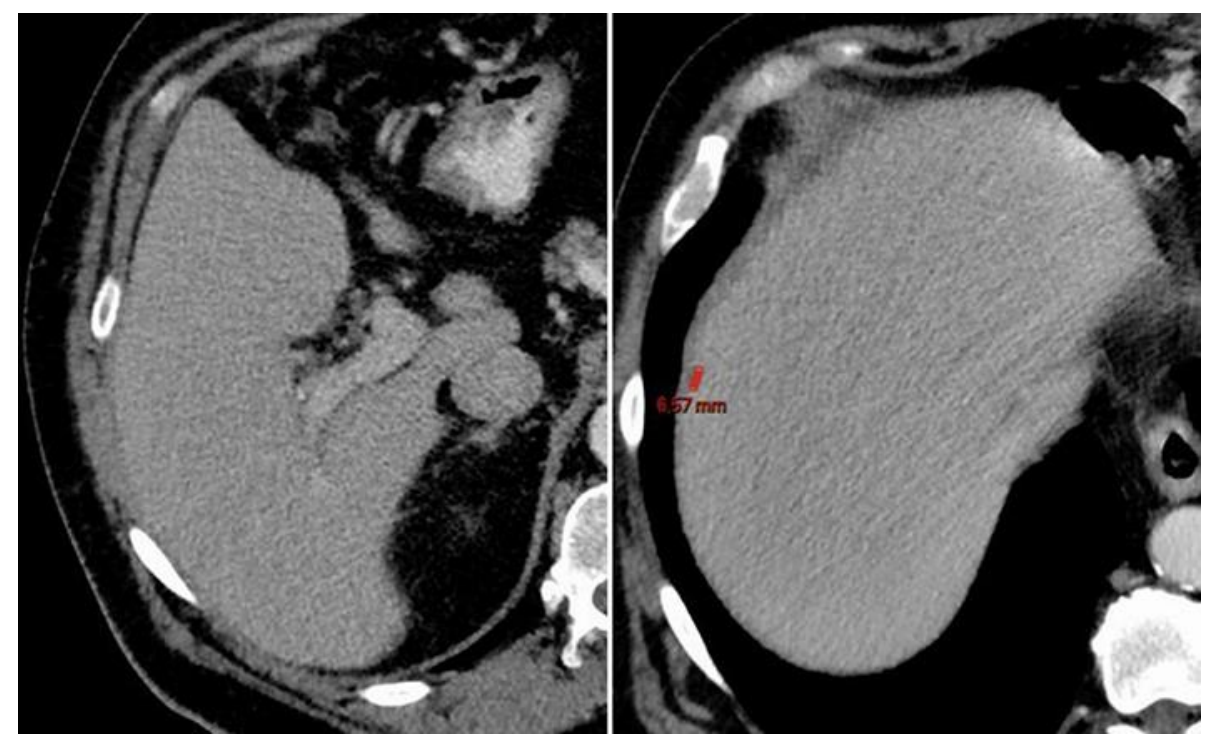

Fig. 2. Subsequent computed tomography evaluation $(04 / 17 / 2013)$ showing the complete disappearance of non-target liver lesions and a reduction in the sum of the longest diameter of target lesions to $7 \mathrm{~mm}$ $(0+7 \mathrm{~mm})$. Partial response was $\approx 85 \%$. 


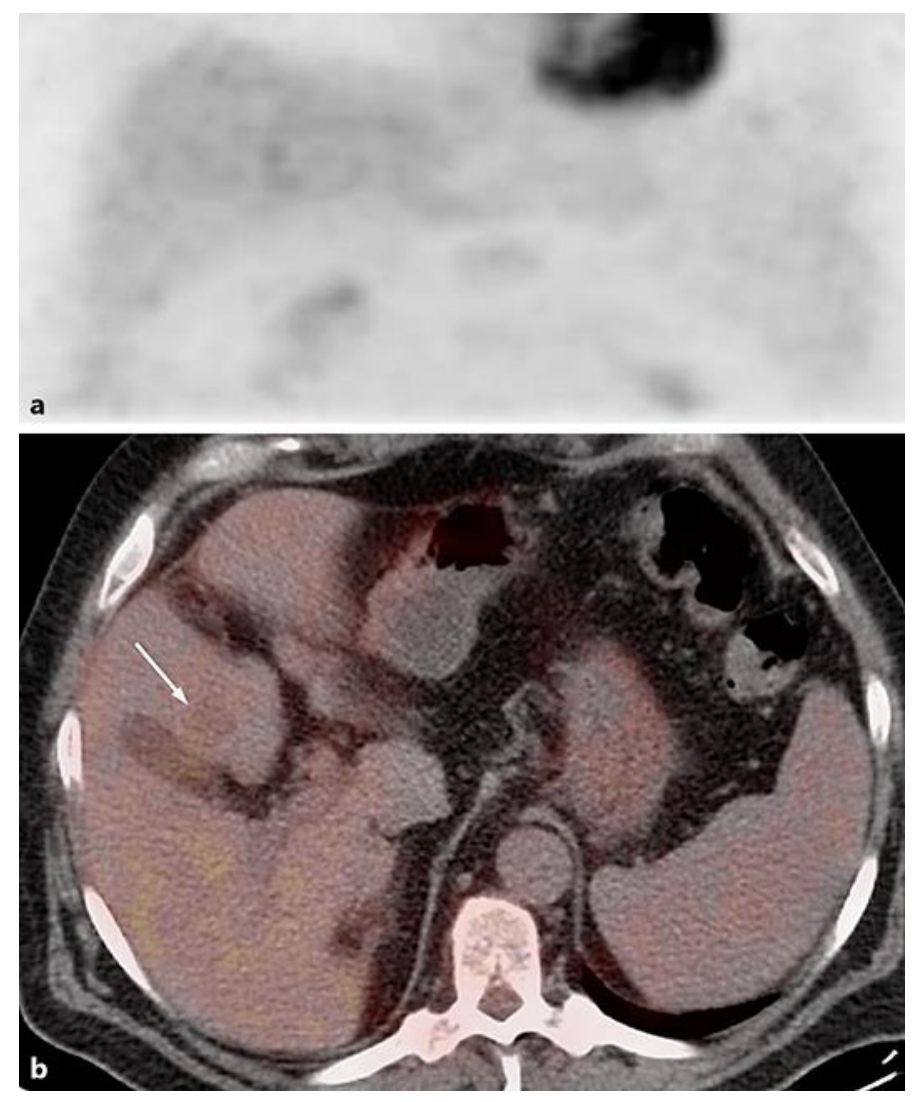

Fig. 3. Positron emission tomography (PET)-computed tomography (CT) scan (07/23/2014) showing no hypermetabolism in either the liver (a, coronal maximum-intensity projection reconstruction of the liver area) or, particularly, the lesion in segment IV (arrow) (b, fusion PET and CT). 